\title{
A Trend Analysis of Temperature in Selected Stations in Nigeria Using Three Different Approaches
}

\author{
Dakéga Saberma Ragatoa1,2*, Kehinde Olufunso Ogunjobi1,3, \\ Appollonia Aimiosino Okhimamhe ${ }^{1,2}$, Sabastine Dekaa Francis ${ }^{4}$, Lucette Adet ${ }^{1,2}$ \\ ${ }^{1}$ West African Science Service Centre on Climate Change and Adapted Land Use (WASCAL), Accra, Ghana \\ ${ }^{2}$ Federal University of Technology Minna (FUT Minna), Minna, Nigeria \\ ${ }^{3}$ Federal University of Technology Akure (FUTA), Akure, Nigeria \\ ${ }^{4}$ Nigerian Meteorological Agency (NiMet), Abuja, Nigeria \\ Email: ^rmandavid@gmail.com, *ragatoa.d@edu.wascal.org
}

How to cite this paper: Ragatoa, D.S., Ogunjobi, K.O., Okhimamhe, A.A., Francis, S.D. and Adet, L. (2018) A Trend Analysis of Temperature in Selected Stations in Nigeria Using Three Different Approaches. Open Access Library Journal, 5: e4371. https://doi.org/10.4236/oalib.1104371

Received: January 24, 2018

Accepted: February 24, 2018

Published: February 27, 2018

Copyright $\odot 2018$ by authors and Open Access Library Inc.

This work is licensed under the Creative Commons Attribution International License (CC BY 4.0).

http://creativecommons.org/licenses/by/4.0/

(c) (i) Open Access

\begin{abstract}
This study used daily observation data obtained from the Nigerian Meteorological Agency (NiMet) to investigate the temperature trend of Nigeria from 1981-2015. The data were homogenised using the Quantile Matching (QM) method and Quality Controlled. The data have been transformed into three sets of data with different periods: daily, monthly and yearly. The datasets (daily, monthly and yearly) were checked for autocorrelation and if they were found auto correlated, the Modified Mann Kendall (MMK) and the PreWhitening (PW) methods were used and compared, if not the normal Mann Kendall (MK) test was applied. The results showed for the different methods, variations in the trend from one station to another and for the minimum and maximum temperature. These variations were observed in the different methods and data screening the performance of each of the methods in the datasets. The general trend was found to be increasing. The variations in the temperature increase the Diurnal Temperature Range (DTR) that impact human health and increase the probability of occurrence of extreme events.
\end{abstract}

\section{Subject Areas}

Atmospheric Sciences, Environmental Sciences

\section{Keywords}

Trend, Homogenisation, Modified Mann-Kendall, Pre-Whitening, Climate Change 


\section{Introduction}

A trend is a long-term change (increase or decrease) in a time series. A trend analysis is ordinarily used in climatology to know how the temperature for example, changes with time. It is also useful in predicting the future behaviour of climate parameters. In Africa temperature and precipitation are the two most studied parameters in terms of past, present and future trend because of the economy that is based mainly on agriculture [1]-[7]. Knowing and controlling the two parameters is very important to maximise the agricultural production. Regional temperature and rainfall over the West Africa region have changed with the time and this has caused damages to the ecosystems and the interrelationships between them [8]-[15]. Trend analysis has been greatly carried on different parameters in many part of the world [16]-[25]. The Mann Kendall (MK) trend test have been widely used and adapted several times in different studies. The Modified Mann Kendall (MMK) and the Pre-Whitening (PW) methods were developed and applied on auto correlated and noised data to remove the noise and the serial correlation so as to increase the power of the trend analyses and their results [19] [26]-[36].

In Nigeria trend analysis has been done [37]; statistical approaches have been directly used on the data such as the kurtosis and skewness coefficients to detect changes and variations in the temperature and rainfall values. Similarly, [38] did in the South West of Nigeria a study on trend and variability of temperature. $\mathrm{He}$ used the least square regression and the normal Mann Kendall to determine the trend and applied the t-test and the standardized index to detect variability in the temperature. In this study observation data were first obtained from the $\mathrm{Ni}$ gerian Meteorological Agency and Quality Controlled. The data were further transformed into three datasets with different time periods; daily, monthly and yearly data that were then auto correlated to detect serial correlation in the different datasets; if they were found auto correlated, the two methods (MMK and $\mathrm{PW}$ ) were used to evaluate the trends without losing the power of the results, if not the normal MK test was applied. A comparison was then made between them especially the MMK and PW to detect the power and the circumstances of each of the applied method.

\section{Materials and Methods}

\subsection{The Study Area}

Figure 1 shows the study area, Nigeria, one of the biggest countries in West Africa in terms of land mass and population. The country covers a land mass of approximately 923,769 square kilometres $\left(\mathrm{km}^{2}\right.$ ), (with $909,890 \mathrm{~km}^{2}$ of land area and $13,879 \mathrm{~km}^{2}$ of water area) [39].

The twentieth century has been among the driest periods of the last several centuries; the well-advertised droughts of the 1970s and 1980s were only the latest of several significant such episodes to affect West Africa in this century. At least two of these droughts have severely affected large areas of Northern Nigeria 


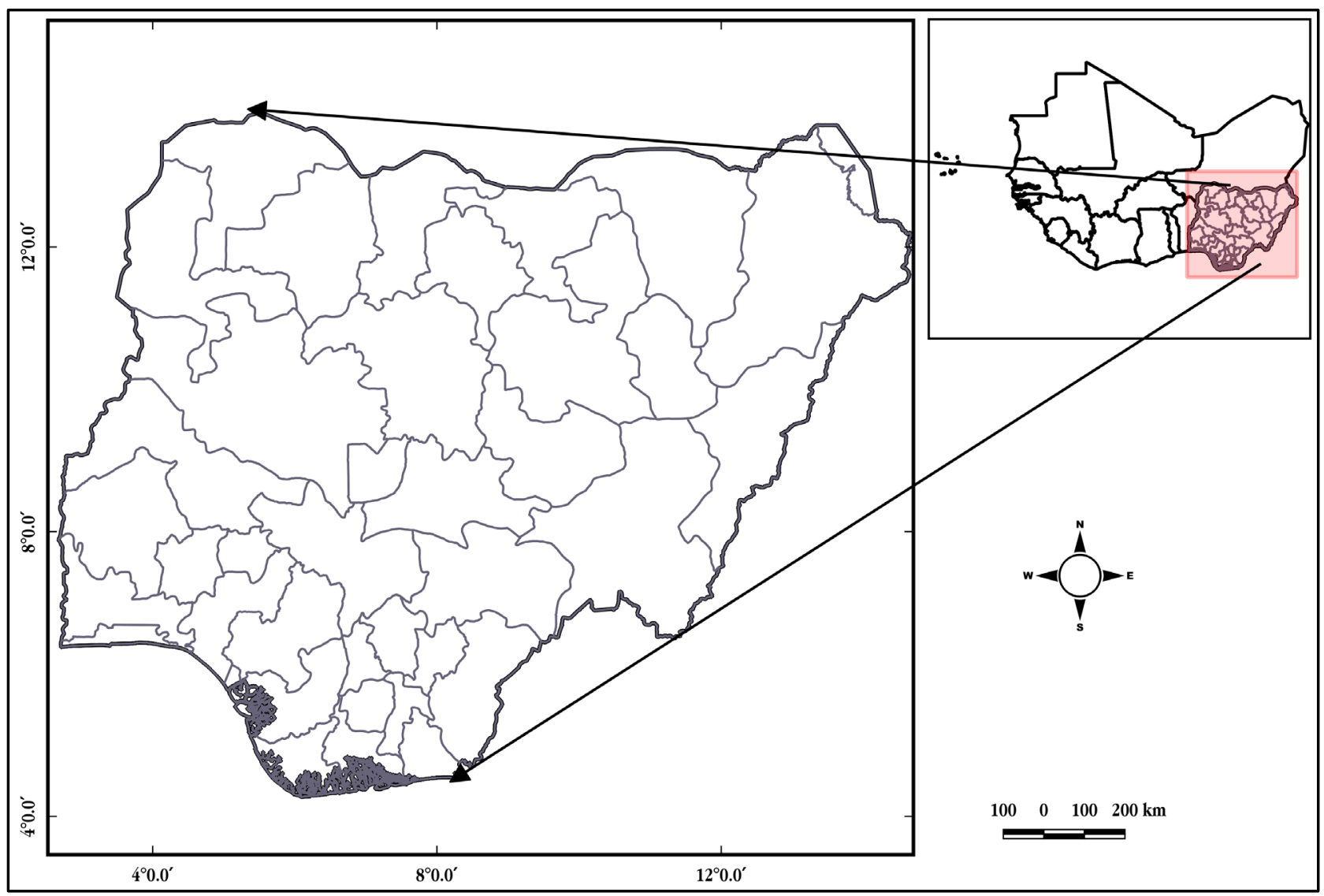

Figure 1. Study area.

and the Sahel. These drought periods are indications of the great variability of climate across tropical Africa and across Nigeria, the most serious effects of which are usually felt at the drier margins of agricultural zones or in the regions occupied primarily by pastoral groups. Although average temperatures vary little from coastal to inland areas, except the North East of Nigeria which has greater extremes [40]. Nigeria was selected in this study because of its exposure to extreme events such as droughts and heat waves recorded in 2016 in Lagos and because it covers five climatic zones in West Africa. Nigeria could then be representative of the West Africa.

\subsection{Materials}

Observed daily temperature data from synoptic stations across Nigeria for a period of thirty-five (35) years were acquired from the Nigerian Meteorological Agency (NiMet) archives. The dataset includes minimum and maximum temperatures (TMIN and TMAX respectively) for 17 stations from 1981-2015 (Table 1 shows the 17 stations). The data were used to detect minimum and maximum temperature trends in Nigeria. The stations were chosen taking into account the different climatic zones of the country (the Coastal, the Tropical Rainforest, the Guinea Savannah, the Sudan Savannah and the Sahel) in order to cover all the country and the stations were to have continuous record over the 
Table 1. List of stations.

\begin{tabular}{cccc}
\hline Station & Latitude & Longitude & Elevation $(\mathrm{m})$ \\
\hline Asaba & 6.20 & 6.73 & 46 \\
Benin & 6.32 & 5.60 & 80 \\
Calabar & 4.97 & 8.35 & 63 \\
Eket & 4.65 & 7.94 & 14 \\
Ikeja & 6.60 & 3.35 & 38 \\
Jos & 9.93 & 8.89 & 1290 \\
Kaduna & 10.52 & 7.44 & 632 \\
Lokoja & 7.81 & 6.74 & 44 \\
Maiduguri & 11.83 & 13.15 & 354 \\
Minna & 9.60 & 6.55 & 260 \\
Oshogbo & 7.78 & 4.54 & 304 \\
Sokoto & 13.02 & 5.25 & 302 \\
Uyo & 5.04 & 7.91 & 38 \\
Warri & 5.52 & 5.73 & 6 \\
Yelwa & 10.88 & 4.75 & 243 \\
Yola & 9.23 & 12.47 & 174 \\
Zaria & 11.13 & 7.68 & 664 \\
\hline
\end{tabular}

period 1981-2015 with less or no missing data. (Figure 2)

\subsection{Methods}

The collected observation data needed to be convert and prepared for the processing and analysis. Thus, the data were converted into ASCII comma separated values (.CSV) files as required for homogenisation using "RHTest" package in R statistics software. All the columns were structured as following sequences: YEAR, MONTH, DAY, TMAX, TMIN (the unit is the degrees Celsius). The two files were converted into time series (TS) using R statistics software.

The data were tested for homogeneity, as homogeneous data are highly recommended in most of climate analysis [41] [42] [43]. The homogenisation was done to detect change-points/breakpoints in the data and adjust them for further analysis. This was necessary in order to avoid biased results [44] [45] [46]. For that purpose, the Quantile Matching (QM) method was applied to the data for adjustment using RHTests4 [47] [48] package in R statistics software. A Quality Control (QC) was carried on the data using the QC function of the World Meteorological Organisation (WMO) Expert Team on Sector-specific Climate Indices (ET-SCI) ClimPACT2 software to detect duplicates, missing values, outliers and relation TMAX/TMIN values as TMAX is logically higher than TMIN. This analysis reduced the number of stations from 17 to 11 stations (Table 2 shows the maintained stations). The stations that were not considered showed anomalies after the homogenisation such as TMIN > TMAX. 


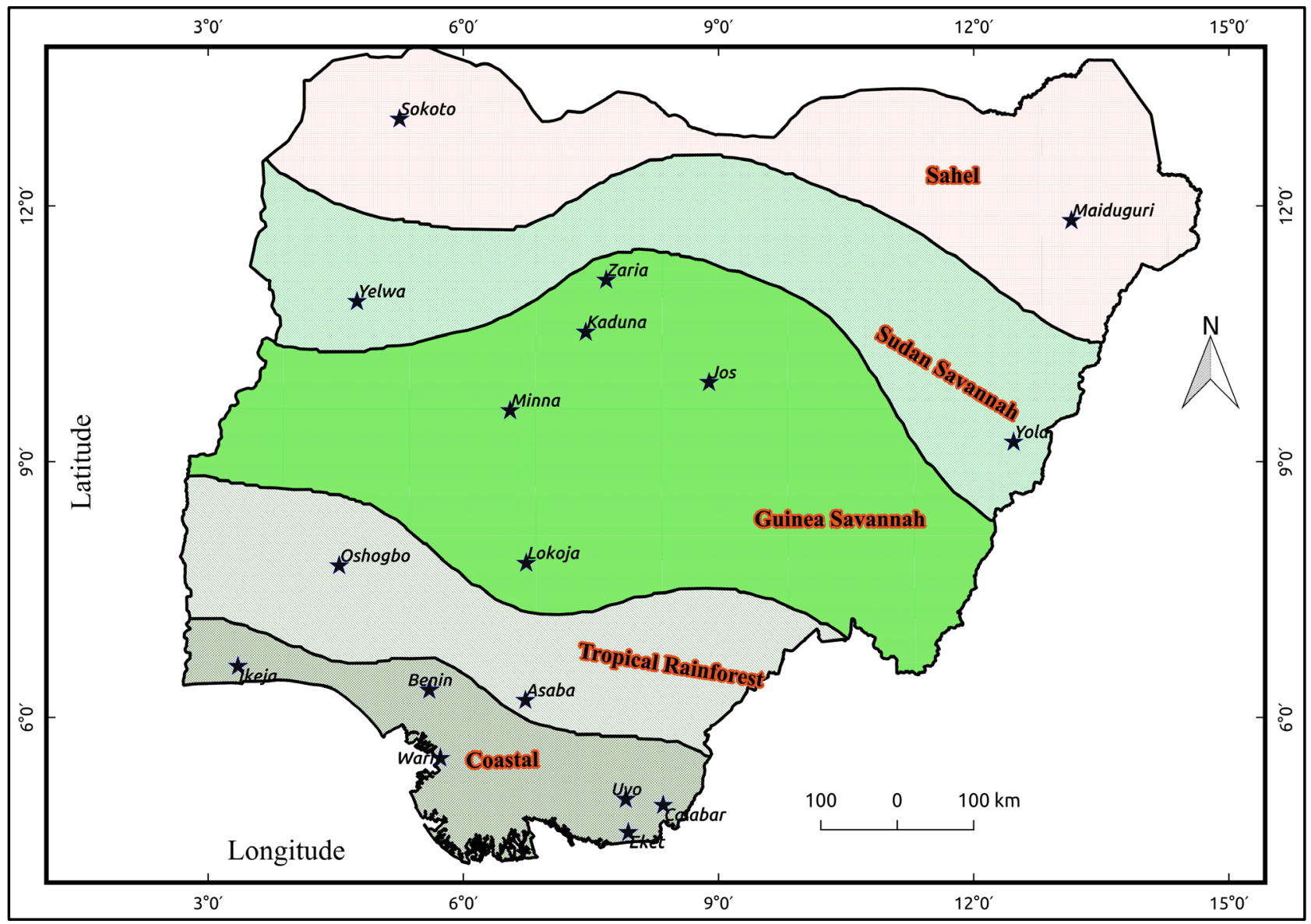

Figure 2. Distribution of stations in the climatic zones of the study area.

Table 2. List of suited stations.

\begin{tabular}{cccc}
\hline Station & Latitude & Longitude & Elevation (m) \\
\hline Asaba & 6.20 & 6.73 & 46 \\
Benin & 6.32 & 5.60 & 80 \\
Calabar & 4.97 & 8.35 & 63 \\
Eket & 4.65 & 7.94 & 14 \\
Ikeja & 6.60 & 3.35 & 38 \\
Kaduna & 10.52 & 7.44 & 632 \\
Lokoja & 7.81 & 6.74 & 44 \\
Oshogbo & 7.78 & 4.54 & 304 \\
Uyo & 5.04 & 7.91 & 38 \\
Warri & 5.52 & 5.73 & 6 \\
Yelwa & 10.88 & 4.75 & 243 \\
\hline
\end{tabular}

To analyse the trend in the temperature time series, the daily data of each station are transformed into monthly and yearly data using a mean based function for calculation as the temperature data is being analysed. An autocorrelation was carried on each station using not only the daily dataset but also the monthly and 
yearly datasets. The autocorrelation was carried on to determine the serial correlation in the datasets. The autocorrelation test is given by Equation (1):

$$
\rho(k)=\frac{\frac{1}{n-k} \sum_{t=k+1}^{n}\left(y_{t}-\bar{y}\right)\left(y_{t-k}-\bar{y}\right)}{\sqrt{\frac{1}{n} \sum_{t=1}^{n}\left(y_{t}-\bar{y}\right)} \sqrt{\frac{1}{n}-k \sum_{t=k+1}^{n}\left(y_{t-k}-\bar{y}\right)}}
$$

where $\bar{y}$ is the sample mean of the data, $n$ is the number of sample.

The climate data as time series over the 1981-2015 period were subjected to the Mann-Kendall (MK) and Sen's Slope tests in order to discover or determine the existence of trends in the time series [34] [35] [36] [49]-[54]. This method developed by Mann (1945) and Kendall (1975) and subsequently modified by Sneyers (1990) is a well-known and used non-parametric method. The simple Mann-Kendall test, a non-parametric statistical test was carried on the dataset with no autocorrelation in the time series, while the Modified Mann-Kendall (MMK) [19] [27] and the Pre-Whitening (PW) [35] [55] methods were applied in case the dataset was revealed to be serially correlated. The last two methods were compared to evaluate their performance. The magnitudes of the slopes of the time series were measured using Sen's Slope method. The Mann-Kendall statistic test is given by Equation (2):

$$
S=\sum_{i=1}^{n-1} \sum_{j=i-1}^{n} \operatorname{Sgn}\left(X_{j}-X_{i}\right)
$$

where $X_{i}$ and $X_{j}$ are the sequential data values, $n$ is the data set record length.

This methodology was developed using the homogenisation and quality control of the station data before proceeding to the trend analysis using three different methods where not only the normal Mann-Kendall method was used (annual data), but also the MMK and PW methods were used and compared. The applied method is recent and good to explore since it is advised that the climatological data is homogenised and quality controlled before further analysis to harmonise and remove breaks. It has also been proved in previous studies [19] [27] [33] [34] [35] [36] that the auto correlated data should be processed using a Bootstrap or MMK or the Trend Free Pre-Whitening (TFPW) method to remove the noise. This method is bringing different view on trends in Nigeria.

\section{Results}

\subsection{Daily Trend}

The autocorrelation on the daily maximum and minimum data revealed a strong serial correlation in the time series for all the stations. The Modified Mann-Kendall (MMK) was then applied to the temperature time series of each station data from 1981-2015. The MMK results are presented on the Table 3. The MMK test appeared to be strongly significant before adjustment, but the corrected p-value was less significant. The values of MK tau $(\tau)$ were significantly low leading to equivalently low statistical trend of the series. The slope of 
Theil-Sen (Sen's Slope) was also significantly close to zero confirming the low magnitude of the trend. The results of the MMK test on the different sites revealed a significant but very low trend in general for TMAX. Benin, Lokoja and Yelwa had non-significant ( $\mathrm{p}$-value $>0.05$ ) trends for both the calculated and the corrected $p$-value. The Kendall tau are very low and their slopes are equal to 0 , no statistical trend. Kaduna had a highly significant trend in the non-corrected p-value (0.000017) and a less high significant trend in the corrected one (0.02241) but the magnitude is equal to 0 . The PW method test is also widely applied to resolve serial correlation in auto correlated times series and to improve on the trend analysis. The results (Table 4) of the test showed significant trends for all the stations and a negative magnitude for all the stations. The upper and lower confidence interval bounds for the slope were all negative except for Warri were the upper bound is equal to 0 . The de-trended time series autocorrelation was very high. The linear regression slopes of the stations were also negative for all the stations.

For TMIN the MMK results on Table 5 showed that the corrected p-values are significant for all the stations except for Eket that had a non-significant trend. The slopes were very low in all the stations, but Ikeja alone recorded a negative slope. The results of PW method presented on Table 6 revealed non-significant trends for Asaba, Lokoja, Oshogbo, Warri and Yelwa. The overall trend for each station was positively very low, with only Eket station having a negative relatively high trend.

Table 3. Modified Mann Kendall test results of daily maximum temperature data.

\begin{tabular}{cccccccc}
\hline Stations & $\mathrm{Z}$ & $\mathrm{p}$-value & $\mathrm{Zc}$ & Corr. p-value & tau & $\mathrm{N} / \mathrm{N}^{*}$ s & Sen's Slope \\
\hline Asaba & -12.374 & $3.608 \mathrm{E}-35$ & -7.391 & $1.452 \mathrm{E}-13$ & -0.0730 & 2.803 & -0.0000736300 \\
Benin & -0.884 & $3.764 \mathrm{E}-01$ & -0.206 & $8.364 \mathrm{E}-01$ & -0.0052 & 18.348 & 0.0000000000 \\
Calabar & 49.933 & $0.000 \mathrm{E}+00$ & 16.134 & $1.469 \mathrm{E}-58$ & 0.2945 & 9.578 & 0.0001167640 \\
Eket & 14.714 & $5.280 \mathrm{E}-49$ & 3.607 & $3.103 \mathrm{E}-04$ & 0.0867 & 16.643 & 0.0000508075 \\
Ikeja & 35.516 & $2.767 \mathrm{E}-276$ & 23.590 & $4.863 \mathrm{E}-123$ & 0.2094 & 2.267 & 0.0001843318 \\
Kaduna & 4.300 & $1.705 \mathrm{E}-05$ & 2.283 & $2.241 \mathrm{E}-02$ & 0.0253 & 3.547 & 0.0000000000 \\
Lokoja & 0.103 & $9.177 \mathrm{E}-01$ & 0.066 & $9.477 \mathrm{E}-01$ & 0.0006 & 2.481 & 0.0000000000 \\
Oshogbo & 12.814 & $1.371 \mathrm{E}-37$ & 7.667 & $1.761 \mathrm{E}-14$ & 0.0756 & 2.793 & 0.0000437563 \\
Uyo & 24.134 & $1.099 \mathrm{E}-128$ & 17.046 & $3.745 \mathrm{E}-65$ & 0.1423 & 2.005 & 0.0001289629 \\
Warri & 10.528 & $6.421 \mathrm{E}-26$ & 6.577 & $4.797 \mathrm{E}-11$ & 0.0621 & 2.562 & 0.0000468323 \\
Yelwa & 3.489 & $4.840 \mathrm{E}-04$ & 1.417 & $1.565 \mathrm{E}-01$ & 0.0206 & 6.064 & 0.0000000000 \\
\hline
\end{tabular}

1) $\mathrm{Z}$ is the original (uncorrected) Mann-Kendall test $\mathrm{Z}$ statistic. 2) p-value is the original (uncorrected) Mann-Kendall test p-value. 3) $\mathrm{Zc}$ is the corrected $\mathrm{Z}$ statistic. 4) Corr. p-value is the corrected p-value considering the autocorrelation. 5) tau is the Mann-Kendall's tau statistic. 6) $N / n^{\star} s$ is the Value of the correction factor standing for the ratio of the number of samples $\mathrm{N}$ divided by the effective sample size $\left.\left(\mathrm{n}^{*} \mathrm{~s}\right) .7\right)$ Sen's Slope is the slope/magnitude of the linear trend according to Sen test. 
Table 4. Pre-Whitening test results of daily maximum temperature data.

\begin{tabular}{ccccccccccc}
\hline Stations & lbound & trend & trendp & ubound & tau & p-value & autocor & valid_frac & linear & intercept \\
\hline Asaba & -0.0045 & -0.0033 & -2.310 & -0.00262 & -0.0927 & 0.000291 & 0.7052 & 1 & -0.003886046 & 35.41285 \\
Benin & -0.0039 & -0.0031 & -2.137 & -0.00212 & -0.1040 & 0.000046 & 0.6630 & 1 & -0.003495636 & 33.35541 \\
Calabar & -0.0011 & -0.0006 & -0.431 & -0.00015 & -0.0713 & 0.004825 & 0.5805 & 1 & -0.001676837 & 31.65528 \\
Eket & -0.0023 & -0.0017 & -1.224 & -0.00115 & -0.1063 & 0.000027 & 0.6677 & 1 & -0.001855519 & 28.79394 \\
Ikeja & -0.0037 & -0.0030 & -2.134 & -0.00233 & -0.0970 & 0.000156 & 0.7445 & 1 & -0.003707738 & 33.00451 \\
Kaduna & -0.0035 & -0.0024 & -1.697 & -0.00072 & -0.0522 & 0.040016 & 0.8243 & 1 & -0.002845725 & 32.54061 \\
Lokoja & -0.0041 & -0.0030 & -2.102 & -0.00203 & -0.0769 & 0.002588 & 0.7564 & 1 & -0.003700171 & 32.89766 \\
Oshogbo & -0.0048 & -0.0037 & -2.580 & -0.00279 & -0.1020 & 0.000059 & 0.7540 & 1 & -0.004242316 & 31.89032 \\
Uyo & -0.0035 & -0.0027 & -1.898 & -0.00184 & -0.1036 & 0.000046 & 0.6882 & 1 & -0.002764263 & 33.71527 \\
Warri & -0.0029 & -0.0020 & -1.431 & 0.00000 & -0.0710 & 0.005568 & 0.7014 & 1 & -0.002637105 & 32.41589 \\
Yelwa & -0.0051 & -0.0037 & -2.612 & -0.00258 & -0.0555 & 0.029356 & 0.8117 & 1 & -0.004180887 & 35.46455 \\
\hline
\end{tabular}

1) lbound is the lower bound of the trend's confidence interval. 2) trend is the Sen's slope (trend) per unit time. 3) trendp is the Sen's slope (trend) over the time period. 4) ubound is the upper bound of the trend's confidence interval. 5) tau is Kendall's tau statistic computed on the final de-trended time series. 6) p-value is Kendall's p-value computed for the final de-trended time series. 7) autocor is the autocorrelation of the final de-trended time series. 8) Valid_frac is the fraction of the data which is valid once autocorrelation is removed. 9) linear is the least squares fit trend on the same data. 10) intercept is the intercept of the Sen's Slope (trend).

Table 5. MMK test results of daily minimum temperature data.

\begin{tabular}{|c|c|c|c|c|c|c|c|}
\hline Stations & $\mathbf{Z}$ & p-value & $\mathrm{Zc}$ & Corr. p-value & tau & $\mathrm{N} / \mathrm{N}^{*} \mathrm{~s}$ & Sen's Slope \\
\hline Asaba & 33.3999 & $1.377 \mathrm{E}-244$ & 11.44085 & $2.6132 \mathrm{E}-30$ & 0.19696 & 8.5226 & 0.00013 \\
\hline Benin & 42.4154 & $0.000 \mathrm{E}+000$ & 30.61594 & $7.5110 \mathrm{E}-206$ & 0.24992 & 1.9193 & 0.00014 \\
\hline Calabar & 33.6190 & $8.864 \mathrm{E}-248$ & 23.37139 & $8.3537 \mathrm{E}-121$ & 0.19812 & 2.0692 & 0.00009 \\
\hline Eket & 2.5380 & $1.115 \mathrm{E}-002$ & 1.47272 & $1.4083 \mathrm{E}-01$ & 0.01497 & 2.9699 & 0.00002 \\
\hline Ikeja & -27.3672 & $6.740 \mathrm{E}-165$ & -12.80005 & $1.6385 \mathrm{E}-37$ & -0.16129 & 4.5713 & -0.00010 \\
\hline Kaduna & 7.6666 & $1.766 \mathrm{E}-014$ & 4.50675 & $6.5829 \mathrm{E}-06$ & 0.04509 & 2.8939 & 0.00000 \\
\hline Lokoja & 26.3244 & $1.009 \mathrm{E}-152$ & 21.33255 & $5.6635 \mathrm{E}-101$ & 0.15473 & 1.5228 & 0.00013 \\
\hline Oshogbo & 13.5189 & $1.209 \mathrm{E}-041$ & 5.76806 & $8.0000 \mathrm{E}-09$ & 0.07967 & 5.4932 & 0.00001 \\
\hline Uyo & 31.9123 & $1.803 \mathrm{E}-223$ & 14.45624 & $2.2897 \mathrm{E}-47$ & 0.18811 & 4.8731 & 0.00010 \\
\hline Warri & 61.1400 & $0.000 \mathrm{E}+000$ & 41.31460 & $0.0000 \mathrm{E}+00$ & 0.36040 & 2.1900 & 0.00022 \\
\hline
\end{tabular}

Table 6. PW test results of daily minimum temperature data.

\begin{tabular}{ccccccccccc}
\hline Stations & lbound & trend & trendp & ubound & tau & p-value & autocor & valid_frac & linear & intercept \\
\hline Asaba & $4.796 \mathrm{E}-05$ & $8.475 \mathrm{E}-05$ & 0.0593 & 0.000118 & 0.0268 & 0.2908 & 0.5827 & 1 & 0.000768 & 20.607 \\
Benin & $0.000 \mathrm{E}+00$ & $0.000 \mathrm{E}+00$ & 0.0000 & 0.000000 & -0.0906 & 0.0005 & 0.4886 & 1 & -0.001039 & 18.620 \\
Calabar & $0.000 \mathrm{E}+00$ & $0.000 \mathrm{E}+00$ & 0.0000 & 0.000000 & -0.0777 & 0.0028 & 0.3025 & 1 & -0.000688 & 21.210 \\
Eket & $-8.421 \mathrm{E}-04$ & $-7.143 \mathrm{E}-04$ & -0.5000 & -0.000656 & -0.1165 & 0.0000 & 0.4100 & 1 & -0.001990 & 20.605 \\
Ikeja & $0.000 \mathrm{E}+00$ & $0.000 \mathrm{E}+00$ & 0.0000 & 0.000000 & -0.0701 & 0.0069 & 0.5945 & 1 & -0.001431 & 21.670 \\
Kaduna & $0.000 \mathrm{E}+00$ & $0.000 \mathrm{E}+00$ & 0.0000 & 0.000235 & 0.0269 & 0.2909 & 0.7986 & 1 & 0.001306 & 20.000 \\
Lokoja & $0.000 \mathrm{E}+00$ & $0.000 \mathrm{E}+00$ & 0.0000 & 0.000000 & -0.0255 & 0.3195 & 0.7810 & 1 & -0.000313 & 15.740 \\
Oshogbo & $0.000 \mathrm{E}+00$ & $0.000 \mathrm{E}+00$ & 0.0000 & 0.000000 & -0.0392 & 0.1270 & 0.6826 & 1 & -0.000697 & 13.530 \\
Uyo & $0.000 \mathrm{E}+00$ & $0.000 \mathrm{E}+00$ & 0.0000 & 0.000000 & -0.0652 & 0.0113 & 0.4387 & 1 & -0.000676 & 18.790 \\
Warri & $0.000 \mathrm{E}+00$ & $0.000 \mathrm{E}+00$ & 0.0000 & 0.000000 & -0.0496 & 0.0551 & 0.3637 & 1 & -0.000477 & 18.150 \\
Yelwa & $0.000 \mathrm{E}+00$ & $0.000 \mathrm{E}+00$ & 0.0000 & 0.000000 & -0.0161 & 0.5269 & 0.8692 & 1 & 0.000481 & 20.330 \\
\hline
\end{tabular}




\subsection{Monthly Trends}

The monthly datasets showed autocorrelation in the time series, necessity the use of the MMK and the PW methods. The transformed daily TMAX data into monthly TMAX data showed for the MMK that the trends in Benin, Lokoja and Yelwa stations were not statistically significant $(>0.05)$ both for the calculated and the corrected $\mathrm{p}$-value. The $\mathrm{Z}$ statistic confirmed by the Kendall tau showed that there is a trend. The Kendall tau is low varying from 0.00038 in Lokoja to 0.338 in Asaba. Benin station had a negative Kendall tau that is confirmed by the Sen's Slope value which was also negative. Lokoja station had no trend (Sen's Slope $=0$ ). All the other stations apart from Lokoja and Benin had a positive and low magnitude. For example, Kaduna station that had "Non Available" Kendall calculated $\mathrm{Z}$ statistic and the corrected $\mathrm{p}$-value revealed an increase in the temperature of $0.001^{\circ} \mathrm{C}$ for the considered period in Table 7 .

The PW method used for monthly TMAX dataset showed a negative Kendall tau for Asaba and Benin stations. The linear regression also was negative for the two stations. The linear regression also showed negative values for Lokoja station. The monthly slope trend of Asaba station was found to be negative displaying a downward trend, likewise, the overall trend (trend over the 35 years). The trends for the other stations were all positive both for the monthly trend and the overall trend except for Lokoja station that had no trend (slope $=0$ ) for the monthly trend and very low slope $\left(0.0044^{\circ} \mathrm{C}\right)$ for the overall trend. The trends of the stations were not statistically significant as the p-values were all greater than 0.05 $(\alpha>0.05)$ except for Calabar station that showed positively low but statistically significant trend (see Table 8).

Table 7. MMK test results of monthly maximum temperature data.

\begin{tabular}{cccccccc}
\hline Stations & $\mathbf{Z}$ & $\mathrm{p}$-value & $\mathrm{Zc}$ & Corr. -value & tau & N/N*s & Sen's Slope \\
\hline Asaba & 10.3572 & $3.8833 \mathrm{E}-25$ & 4.5599828 & $5.11578 \mathrm{E}-06$ & 0.33833 & 5.158872 & 0.00474 \\
Benin & -1.0698 & $2.8469 \mathrm{E}-01$ & -1.2203395 & $2.22336 \mathrm{E}-01$ & -0.03496 & 0.768567 & -0.00092 \\
Calabar & 8.6524 & $5.0444 \mathrm{E}-18$ & 12.7215357 & $4.48949 \mathrm{E}-37$ & 0.28265 & 0.462584 & 0.00333 \\
Eket & 3.4176 & $6.3175 \mathrm{E}-04$ & 3.5886014 & $3.32457 \mathrm{E}-04$ & 0.11165 & 0.906971 & 0.00181 \\
Ikeja & 7.6163 & $2.6110 \mathrm{E}-14$ & 10.8194042 & $2.78583 \mathrm{E}-27$ & 0.24880 & 0.495540 & 0.00617 \\
Kaduna & 0.8907 & $3.7310 \mathrm{E}-01$ & $\mathrm{NA}$ & $\mathrm{NA}$ & 0.02911 & -1.103138 & 0.00101 \\
Lokoja & 0.0111 & $9.9112 \mathrm{E}-01$ & 0.0104893 & $9.91631 \mathrm{E}-01$ & 0.00038 & 1.126574 & 0.00000 \\
Oshogbo & 2.4758 & $1.3294 \mathrm{E}-02$ & 6.2903000 & $3.16853 \mathrm{E}-10$ & 0.08088 & 0.154911 & 0.00250 \\
Uyo & 5.2842 & $1.2627 \mathrm{E}-07$ & 8.9117183 & $5.02477 \mathrm{E}-19$ & 0.17262 & 0.351587 & 0.00433 \\
Warri & 2.6344 & $8.4277 \mathrm{E}-03$ & 3.0559582 & $2.24343 \mathrm{E}-03$ & 0.08607 & 0.743157 & 0.00174 \\
Yelwa & 0.8235 & $4.1021 \mathrm{E}-01$ & 0.8764292 & $3.80797 \mathrm{E}-01$ & 0.02691 & 0.882917 \\
\hline
\end{tabular}


Table 8. PW test results of monthly maximum temperature data.

\begin{tabular}{ccccccccccc}
\hline Stations & lbound & trend & trendp & ubound & tau & p-value & autocor & valid_frac & linear & intercept \\
\hline Asaba & -0.0062 & -0.0008 & -0.1584 & 0.0047 & -0.0105 & 0.8284 & 0.7765 & 1 & -0.0013 & 34.323 \\
Benin & -0.0053 & 0.0002 & 0.0427 & 0.0053 & -0.0043 & 0.9295 & 0.7804 & 1 & -0.0004 & 32.599 \\
Calabar & 0.0023 & 0.0046 & 0.8971 & 0.0068 & 0.1149 & 0.0174 & 0.7130 & 1 & 0.0042 & 31.413 \\
Eket & 0.0006 & 0.0038 & 0.7503 & 0.0072 & 0.0638 & 0.1866 & 0.7744 & 1 & 0.0035 & 28.263 \\
Ikeja & 0.0024 & 0.0070 & 1.3560 & 0.0117 & 0.0421 & 0.3835 & 0.8009 & 1 & 0.0067 & 32.019 \\
Kaduna & -0.0060 & 0.0008 & 0.1498 & 0.0068 & 0.0028 & 0.9541 & 0.5930 & 1 & 0.0011 & 31.552 \\
Lokoja & -0.0059 & 0.0000 & 0.0044 & 0.0060 & 0.0180 & 0.7102 & 0.7696 & 1 & -0.0003 & 32.361 \\
Oshogbo & -0.0037 & 0.0026 & 0.5152 & 0.0089 & 0.0228 & 0.6375 & 0.7879 & 1 & 0.0021 & 30.800 \\
Uyo & 0.0011 & 0.0062 & 1.2000 & 0.0113 & 0.0774 & 0.1093 & 0.7541 & 1 & 0.0056 & 32.601 \\
Warri & -0.0017 & 0.0025 & 0.4779 & 0.0065 & 0.0181 & 0.7085 & 0.7659 & 1 & 0.0024 & 32.014 \\
Yelwa & -0.0061 & 0.0015 & 0.2881 & 0.0085 & 0.0112 & 0.8181 & 0.6932 & 1 & 0.0009 & 34.559 \\
\hline
\end{tabular}

The TMIN showed a pattern similar to the TMAX in the trend. The MMK showed a statistically significant trend in all the stations both in the calculated p-value and the corrected p-value. Only Lokoja station had a "Non Available" result with the corrected $\mathrm{Z}$ Kendall and $\mathrm{p}$-value, but the calculated ones showed very strong significance. The slopes were all positive but low with only Ikeja station having a negative slope for the period under study (see Table 9).

The PW method for TMIN on Table 10 showed a negative trend value, explaining a downward trend for Ikeja station for both the monthly and the 35 years period. This explains the negative linear regression of the trend of the stations. All the 10 other stations had positive trends for both the monthly and the 35 years' period. Literature reviewed that the overall period (35 years in this study) trend is always greater than the unit trend (monthly trend). From all the trends, only 4 stations (Asaba, Benin, Uyo and Warri) were statistically significant $(\alpha<0.05)$. The other seven $(7)$ stations were not statistically significant.

Table 9. MMK test results of monthly minimum temperature data.

\begin{tabular}{ccccccccc}
\hline Stations & $\mathbf{Z}$ & p-value & $\mathrm{Zc}$ & Corr. p-value & tau & N/N*s & Sen's Slope \\
\hline Asaba & 10.357 & $3.88330 \mathrm{E}-25$ & 4.55998 & $5.11578 \mathrm{E}-06$ & 0.3383 & 5.159 & 0.0047 \\
Benin & 12.397 & $2.72227 \mathrm{E}-35$ & 31.12259 & $1.19168 \mathrm{E}-212$ & 0.4050 & 0.159 & 0.0048 \\
Calabar & 10.767 & $4.90707 \mathrm{E}-27$ & 19.56538 & $3.05140 \mathrm{E}-85$ & 0.3517 & 0.303 & 0.0033 \\
Eket & 2.558 & $1.05204 \mathrm{E}-02$ & 2.98983 & $2.79131 \mathrm{E}-03$ & 0.0836 & 0.732 & 0.0015 \\
Ikeja & -8.543 & $1.31016 \mathrm{E}-17$ & -6.76118 & $1.36876 \mathrm{E}-11$ & -0.2791 & 1.596 & -0.0034 \\
Kaduna & 1.892 & $5.84908 \mathrm{E}-02$ & 3.05120 & $2.27928 \mathrm{E}-03$ & 0.0618 & 0.385 & 0.0015 \\
Lokoja & 6.319 & $2.62794 \mathrm{E}-10$ & NA & NA & 0.2064 & -0.474 & 0.0043 \\
Oshogbo & 3.134 & $1.72410 \mathrm{E}-03$ & 7.22762 & $4.91541 \mathrm{E}-13$ & 0.1024 & 0.188 & 0.0013 \\
Uyo & 10.658 & $1.59164 \mathrm{E}-26$ & 18.04238 & $9.05632 \mathrm{E}-73$ & 0.3482 & 0.349 & 0.0034 \\
Warri & 16.693 & $1.46180 \mathrm{E}-62$ & 29.24242 & $5.60557 \mathrm{E}-188$ & 0.5453 & 0.326 & 0.0068 \\
Yelwa & 7.457 & $8.88000 \mathrm{E}-14$ & 18.83285 & $4.06257 \mathrm{E}-79$ & 0.2436 & 0.157 & 0.0097 \\
\hline
\end{tabular}


Table 10. PW test results of monthly minimum temperature data.

\begin{tabular}{ccccccccccc}
\hline Stations & lbound & trend & trendp & ubound & tau & p-value & autocor & valid_frac & linear & intercept \\
\hline Asaba & 0.0032 & 0.0056 & 1.088 & 0.0079 & 0.1645 & 0.00066 & 0.2433 & 1 & 0.00618 & 20.141 \\
Benin & 0.0029 & 0.0050 & 0.977 & 0.0070 & 0.1518 & 0.00168 & 0.3687 & 1 & 0.00506 & 18.360 \\
Calabar & 0.0013 & 0.0031 & 0.611 & 0.0051 & 0.0893 & 0.06474 & 0.4863 & 1 & 0.00300 & 21.187 \\
Eket & -0.0030 & 0.0007 & 0.127 & 0.0041 & 0.0054 & 0.91193 & 0.4803 & 1 & 0.00101 & 19.634 \\
Ikeja & -0.0062 & -0.0038 & -0.748 & -0.0015 & -0.0886 & 0.06669 & 0.5175 & 1 & -0.00428 & 21.998 \\
Kaduna & -0.0046 & 0.0009 & 0.178 & 0.0060 & -0.0263 & 0.58633 & 0.7213 & 1 & 0.00068 & 19.852 \\
Lokoja & -0.0014 & 0.0032 & 0.620 & 0.0070 & 0.0510 & 0.29136 & 0.5528 & 1 & 0.00256 & 15.349 \\
Oshogbo & -0.0009 & 0.0022 & 0.424 & 0.0052 & 0.0319 & 0.50978 & 0.4295 & 1 & 0.00208 & 13.989 \\
Uyo & 0.0009 & 0.0027 & 0.524 & 0.0046 & 0.0830 & 0.08606 & 0.4478 & 1 & 0.00293 & 18.242 \\
Warri & 0.0050 & 0.0068 & 1.324 & 0.0087 & 0.2053 & 0.00002 & 0.4261 & 1 & 0.00685 & 18.341 \\
Yelwa & -0.0016 & 0.0062 & 1.203 & 0.0136 & 0.0365 & 0.45067 & 0.7150 & 1 & 0.00719 & 19.784 \\
\hline
\end{tabular}

\subsection{Annual Trends}

In the annual trend, the autocorrelation test revealed no serial correlation in the time series. The normal Mann Kendall trend test was then applied on both the TMIN and the TMAX data. The annual trend analyses for TMAX (Table 11) showed a negative $S$ statistic for Asaba and Benin stations confirming the existence of negative monotonic trends. Similarly, the $\mathrm{Z}$ statistic was negative for the two stations. The statistical relationship between the $\mathrm{Z}$ statistic and the Kendall tau negative values were observed in Asaba and Benin stations (where Asaba had $\tau=-0.5361$ and Benin had $\tau=-0.1395$ respectively). The magnitude of the slope was therefore carried on by a negative trend slope of the two stations, only Benin station showed a non-significant trend. Similar to Benin station, Lokoja station showed a non-significant trend though the $S$ revealed a positive trend. Except for Benin and Lokoja stations that had a non-significant trends and Asaba station that showed a negative significant trend, all the stations revealed a positive and significant trend for the TMAX.

Table 11. Mann Kendall test results on yearly maximum temperature data.

\begin{tabular}{ccccccccc}
\hline Stations & $\mathbf{Z}$ & $\mathbf{n}$ & $\mathrm{p}$-value & $\mathrm{S}$ & varS & tau & Sen's Slope & 95 percent confidence interval \\
\hline Asaba & -4.516 & 35 & 0.0000063 & -319 & 4958.33 & -0.5361 & -0.02578 & $-0.03510878--0.01718395$ \\
Benin & -1.165 & 35 & 0.2442 & -83 & 4958.33 & -0.1395 & -0.00633 & $-0.018455342-0.006410959$ \\
Calabar & 6.788 & 35 & 0.0000 & 479 & 4958.33 & 0.8050 & 0.03899 & $0.03458630-0.04380365$ \\
Eket & 4.488 & 35 & 0.0000 & 317 & 4958.33 & 0.5328 & 0.02095 & $0.01272016-0.02850750$ \\
Ikeja & 7.243 & 35 & 0.0000 & 511 & 4958.33 & 0.8588 & 0.07178 & $0.06492097-0.08110274$ \\
Kaduna & 2.812 & 35 & 0.0049 & 199 & 4958.33 & 0.3345 & 0.01507 & $0.006592466-0.024005668$ \\
Lokoja & 0.795 & 35 & 0.4265 & 57 & 4960.00 & 0.0958 & 0.00399 & $-0.005205479-0.013025897$ \\
Oshogbo & 4.857 & 35 & 0.0000 & 343 & 4958.33 & 0.5765 & 0.03012 & $0.02302033-0.04025557$ \\
Uyo & 6.504 & 35 & 0.0000 & 459 & 4958.33 & 0.7714 & 0.05455 & $0.04588951-0.06274249$ \\
Warri & 3.920 & 35 & 0.0001 & 277 & 4958.33 & 0.4655 & 0.02269 & $0.01291507-0.03170091$ \\
Yelwa & 2.357 & 35 & 0.0184 & 167 & 4958.33 & 0.2807 & 0.01701 & $0.002249459-0.031086104$ \\
\hline
\end{tabular}


The annual trend of TMIN revealed a negative monotonic trend in Ikeja station. This is observed from the results depicted on Table 12 with the negative $\mathrm{S}$ and $\mathrm{Z}$ Kendall statistics values where the $Z$ is strongly related to the Kendall tau. The Sen's Slope revealed a negative trend for Ikeja but statistically significant using the p-value. All the other 10 stations had a significant positive trends. This is evident in the slopes that revealed the magnitude and direction of the trend.

Table 12. Mann Kendall test results on yearly minimum temperature data.

\begin{tabular}{ccccccccc}
\hline Stations & $\mathbf{Z}$ & $\mathbf{n}$ & $\mathrm{p}$-value & $\mathrm{S}$ & varS & tau & Sen's Slope & 95 percent confidence interval \\
\hline Asaba & 6.1066 & 35 & 0.00000 & 431 & 4958.333 & 0.7244 & 0.05639 & $0.04250228-0.06686356$ \\
Benin & 6.9019 & 35 & 0.00000 & 487 & 4958.333 & 0.8185 & 0.05921 & $0.05366819-0.06765427$ \\
Calabar & 6.5611 & 35 & 0.00000 & 463 & 4958.333 & 0.7782 & 0.03966 & $0.03307859-0.04510242$ \\
Eket & 2.5563 & 35 & 0.01058 & 181 & 4958.333 & 0.3042 & 0.01850 & $0.005588505-0.033669868$ \\
Ikeja & -6.0782 & 35 & 0.00000 & -429 & 4958.333 & -0.7210 & -0.04128 & $-0.04861883-0.03215952$ \\
Kaduna & 3.3515 & 35 & 0.00080 & 237 & 4958.333 & 0.3983 & 0.02064 & $0.00913242-0.03208904$ \\
Lokoja & 5.6522 & 35 & 0.00000 & 399 & 4958.333 & 0.6706 & 0.05773 & $0.04387763-0.07095408$ \\
Oshogbo & 3.2663 & 35 & 0.00109 & 231 & 4958.333 & 0.3882 & 0.01967 & $0.009215753-0.0299844631$ \\
Uyo & 6.277 & 35 & 0.00000 & 443 & 4958.333 & 0.7445 & 0.03849 & $0.03210228-0.04894521$ \\
Warri & 7.4984 & 35 & 0.00000 & 529 & 4958.333 & 0.8891 & 0.08267 & $0.07718493-0.08942586$ \\
Yelwa & 6.8735 & 35 & 0.00000 & 485 & 4958.333 & 0.8151 & 0.11688 & $0.1030335-0.1292066$ \\
\hline
\end{tabular}

\section{Discussion}

This study showed that there are variabilities of the temperature over time during the period 1981-2015. The variability in the temperature have been observed by [37]. The temperatures had an increasing trend in some stations [38] and a decreasing trend in some other stations. For example, in the daily TMAX data, the MMK showed a low increasing trend over the 35 years except Asaba station that had a low decreasing trend. This shows that the temperature has increased during the period 1981-2015 and will increase in the future years in Nigeria in the actual climate conditions. But the PW test exposed a totally decreasing trend in all the stations both for the unit trend and the 35 years' trend. For the daily data there was a difference in the results presented by the two methods especially for the daily TMAX. The MMK seems to perform wel in that case and moreover, the de-trended and deseasonalised data gave a similar trend to the results obtained by the MMK for each of the stations. In the Table 5 and Table 6 the results showed the trend analysis on minimum temperature data using the MMK and the PW respectively; the PW performed better confirming like in the case of Table 3 and Table 4 the conclusion that the MMK method is a good test for daily data.

For the monthly datasets, the PW method test performed as good as the MMK. The monthly data had a cyclical trend that the pre-whitening could easily remove by removing the noises and de-trending the data. For example, the MMK used for maximum monthly temperature showed a decreasing trend for 
Benin station while the PW showed a decreasing trend for Asaba station with a negative linear regression for both stations. The PW method performed better in this case because the deseasonalised trend data showed a clear decreasing trend for Asaba. Benin station also had a decreasing trend. The PW method revealed the decreasing tendency of Benin station confirmed by the linear regression value. For the minimum monthly temperature, the two tests, MMK and PW method showed the same results whereby Ikeja station had a negative trend slope.

In the case of daily temperature datasets, the autocorrelation test showed no serial correlation over the time. Therefore, the simple Mann Kendall and Sen's Slope were applied on the daily temperature dataset in order to detect the magnitude of the trends. The yearly data have always been easier to handle because in most cases, the noises are less or absent when compared to the monthly and daily data. The MK test showed a negative trend in the TMAX for Asaba and Benin station while a positive trend was observed in the TMIN leading to a decrease in the Diurnal Temperature Range. Similarly, Ikeja station recorded a decreasing trend in the TMIN, while an increasing trend was observed in the TMAX. These variations in the annual temperature trends of TMIN and TMAX in the different stations were also observed for the daily and monthly datasets. This implies that, daily mean temperature is increasing and the DTR which is the difference between the daily TMIN and TMAX, is increasing as well and may lead to health-related issues [56]. Some stations showed an increasing trend for both the TMAX and the TMIN. The stations that recorded an increase in the trend for TMAX and TMIN displayed a general increase in the mean temperature for the different datasets. An increase in the temperature could lead to severe Heat Waves under climate change.

In the three datasets, daily, monthly and annual, the different trends revealed a negative trend of Benin but more for Asaba station when considering the TMAX and a negative trend for Eket and Ikeja stations but the emphases is put on Ikeja station for all the different datasets.

\section{Conclusions}

The transformation of the data in different datasets during the analysis was to study the behaviour of the autocorrelation for the different datasets, daily, monthly and annual. The use and the comparison of the two different approaches, the Modified Mann-Kendall and the Pre-Whitening methods revealed that the daily data could be cumbersome to handle compared to the monthly and especially the yearly data. The comparison of the two methods showed better performance of the MMK method with the daily data, but a good performance of PW method for the monthly data. The two approaches may present some weaknesses, but they are comparable and good for different cases of analysis like choosing the MMK method for daily trend analysis or PW method for monthly trend analysis. The annual data did not require the use of MMK and PW methods because yearly data have less noise and the autocorrelation test reveals no serial correlation in most of the cases. Nigeria is experiencing an in- 
crease in the temperature in almost all the stations and a decrease in some other stations like Ikeja mainly, Asaba and Benin depending on the temperature, minimum or maximum. The mean temperature is increasing in many stations and also the DTR. The increase of the DTR and in the mean temperature could impact communities by affecting the homeostatic mechanism, cardiovascular and respiratory diseases that can lead to death (old people and children), by increasing the malaria development across Nigeria especially in the South. It has been proved that the increase in the temperature threats natural life and lead to the extension of some species.

\section{Acknowledgements}

The authors would like to acknowledge the West African Science Service Centre on Climate Change and Adapted Land Use (WASCAL) and the German Federal Ministry of Research (BMBF) for supporting this research. We acknowledge NiMet for providing the data. Our thanks go to the $\mathrm{R}$ statistic community that provided the functions and packages for the analysis.

\section{References}

[1] Aguilar, E., Barry, A.A., Brunet, M., Ekang, L., Fernandes, A., Massoukina, M., et al. (2009) Changes in Temperature and Precipitation Extremes in Western Central Africa, Guinea Conakry, and Zimbabwe, 1955-2006. Journal of Geophysical Research Atmospheres, 114. https://doi.org/10.1029/2008JD011010

[2] Camberlin, P. (2017) Temperature Trends and Variability in the Greater Horn of Africa: Interactions with Precipitation. Climate Dynamics, 48, 477-498. https://doi.org/10.1007/s00382-016-3088-5

[3] Gbobaniyi, E., Sarr, A., Sylla, M.B., Diallo, I., Lennard, C., Dosio, A., et al. (2014) Climatology, Annual Cycle and Interannual Variability of Precipitation and Temperature in CORDEX Simulations over West Africa. International Journal of Climatology, 34, 2241-2257. https://doi.org/10.1002/joc.3834

[4] James, R. and Washington, R. (2013) Changes in African Temperature and Precipitation Associated with Degrees of Global Warming. Climatic Change, 117, 859-872. https://doi.org/10.1007/s10584-012-0581-7

[5] Nikulin, G., Jones, C., Giorgi, F., Asrar, G., Büchner, M., Cerezo-Mota, R., et al. (2012) Precipitation Climatology in an Ensemble of CORDEX-Africa Regional Climate Simulations. Journal of Climate, 25, 6057-6078. https://doi.org/10.1175/JCLI-D-11-00375.1

[6] O’Loughlin, J., Linke, A.M. and Witmer, F.D.W. (2014) Effects of Temperature and Precipitation Variability on the Risk of Violence in Sub-Saharan Africa, 1980-2012. Proceedings of the National Academy of Sciences of the United States of America, 111, 16712-16717. https://doi.org/10.1073/pnas.1411899111

[7] Shongwe, M.E., van Oldenborgh, G.J., van den Hurk, B. and van Aalst, M. (2011) Projected Changes in Mean and Extreme Precipitation in Africa under Global Warming. Part II: East Africa. Journal of Climate, 24, 3718-3733. https://doi.org/10.1175/2010JCLI2883.1

[8] Bates, B.C., Kundzewicz, Z.W., Wu, S. and Palutikof, J.P., Eds. (2008) Climate Change and Water. Technical Paper of the Intergovernmental Panel on Climate 
Change, IPCC Secretariat, Geneva, 210 p.

[9] Hansen, J., Sato, M. and Ruedy, R. (2012) Perception of Climate Change. Proceedings of the National Academy of Sciences, 109, E2415-E2423. https://doi.org/10.1073/pnas.1205276109

[10] Hulme, M., Doherty, R., Ngara, T., New, M. and Lister, D. (2001) African Climate Change: 1900-2100. Climate Research, 17, 145-168. https://doi.org/10.3354/cr017145

[11] Intergovernmental Panel on Climate Change (2014) Climate Change 2014 Mitigation of Climate Change. Working Group III Contribution to the Fifth Assessment Report of the Intergovernmental Panel on Climate Change.

[12] Loarie, S.R., Duffy, P.B., Hamilton, H., Asner, G.P., Field, C.B. and Ackerly, D.D. (2009) The Velocity of Climate Change. Nature, 462, 1052-1055. https://doi.org/10.1038/nature08649

[13] UNFCCC (2007) Climate Change: Impacts, Vulnerabilities and Adaptation in Developing Countries. United Nations Framework Convention on Climate Change. http://unfccc.int/resource/docs/publications/impacts.pdf

[14] Walther, G.-R., Post, E., Convey, P., Menzel, A., Parmesan, C., Beebee, T.J.C., Bairlein, F., et al. (2002) Ecological Responses to Recent Climate Change. Nature, 416, 389-395. https://doi.org/10.1038/416389a

[15] Wheeler, T. and von Braun, J. (2013) Climate Change Impacts on Global Food Security. Science, 341, 508-513. https://doi.org/10.1126/science.1239402

[16] Baart, F., van Koningsveld, M. and Stive, M.J.F. (2012) Trends in Sea-Level Trend Analysis. Journal of Coastal Research, 280, 311-315. https://doi.org/10.2112/JCOASTRES-11A-00024.1

[17] Brillinger, D.R. (1995) Trend Analysis: Binary-Valued and Point Cases. Stochastic Hydrology and Hydraulics, 9, 207-213. https://doi.org/10.1007/BF01581719

[18] Business Dictionary (2016) Trend Analysis. http://www.businessdictionary.com/definition/trend-analysis.html

[19] Hamed, K.H. and Rao, A.R. (1998) A Modified Mann-Kendall Trend Test for Auto-Correlated Data. Journal of Hydrology, 204, 182-196. https://doi.org/10.1016/S0022-1694(97)00125-X

[20] Hirsch, R.M., Slack, J.R. and Smith, R.A. (1982) Techniques of Trend Analysis for Monthly Water Quality Data. Water Resources Research, 18, 107-121. https://doi.org/10.1029/WR018i001p00107

[21] Jain, S.K. and Kumar, V. (2012) Trend Analysis of Rainfall and Temperature Data for India. Current Science, 102, 37-49.

[22] Kahya, E. and Kalayci, S. (2004) Trend Analysis of Streamflow in Turkey. Journal of Hydrology, 289, 128-144. https://doi.org/10.1016/j.jhydrol.2003.11.006

[23] McSweeney, C. (2012) A Climate Trend Analysis of Ethiopia. Famine Early Warning Systems Network-Informing Climate Change Adaptation Series. http://pubs.usgs.gov/fs/2012/3123/

[24] Partal, T. and Kahya, E. (2006) Trend Analysis in Turkish Precipitation Data. Hydrological Processes, 20, 2011-2026. https://doi.org/10.1002/hyp.5993

[25] Pohlert, T. (2016) Package "Trend": Non-Parametric Trend Tests and Change-Point Detection. R Package, 26.

[26] Bayazit, M., Önöz, B., Yue, S. and Wang, C. (2004) Comment on "Applicability of Pre-Whitening to Eliminate the Influence of Serial Correlation on the 
Mann-Kendall Test” by Sheng Yue and Chun Yuan Wang. Water Resources Research, 40, W03806. https://doi.org/10.1029/2002WR001925

[27] Blain, G. (2013) The Modified Mann-Kendall Test: On the Performance of Three Variance Correction Approaches. Bragantia, Campinas, 72, 416-425.

https://doi.org/10.1590/brag.2013.045

[28] Drapela, K. and Drapelova, I. (2011) Application of Mann-Kendall Test and the Sen's Slope Estimates for Trend Detection in Deposition Data from Bily Kriz (Beskydy Mts., the Czech Republic) 1997-2010. Beskydy, 4, 133-146.

[29] Gocic, M. and Trajkovic, S. (2013) Analysis of Changes in Meteorological Variables using Mann-Kendall and Sen's Slope Estimator Statistical Tests in Serbia. Global and Planetary Change, 100, 172-182. https://doi.org/10.1016/j.gloplacha.2012.10.014

[30] Hamed, K.H. (2009) Exact Distribution of the Mann-Kendall Trend Test Statistic for Persistent Data. Journal of Hydrology, 365, 86-94. https://doi.org/10.1016/j.jhydrol.2008.11.024

[31] Karmeshu, N. (2015) Trend Detection in Annual Temperature \& Precipitation using the Mann Kendall Test-A Case Study to Assess Climate Change on Select States in the Northeastern United States. http://repository.upenn.edu/mes_capstones/47

[32] Neeti, N. and Eastman, J.R. (2011) A Contextual Mann-Kendall Approach for the Assessment of Trend Significance in Image Time Series. Transactions in GIS, 15, 599-611. https://doi.org/10.1111/j.1467-9671.2011.01280.x

[33] Önöz, B. and Bayazit, M. (2012) Block Bootstrap for Mann-Kendall Trend Test of Serially Dependent Data. Hydrological Processes, 26, 3552-3560. https://doi.org/10.1002/hyp.8438

[34] Yue, S. and Pilon, P. (2004) A Comparison of the Power of the T Test, Mann-Kendall and Bootstrap Tests for Trend Detection. Hydrological Sciences Journal, 49, 21-37. https://doi.org/10.1623/hysj.49.1.21.53996

[35] Yue, S., Pilon, P., Phinney, B. and Cavadias, G. (2002) The Influence of Autocorrelation on the Ability to Detect Trend in Hydrological Series. Hydrological Processes, 16, 1807-1829. https://doi.org/10.1002/hyp.1095

[36] Yue, S. and Wang, C.Y. (2002) Applicability of Pre-Whitening to Eliminate the Influence of Serial Correlation on the Mann-Kendall Test. Water Resources Research, 38, 4-1-4-7.

[37] Akinsanola, A. and Ogunjobi, K. (2014) Analysis of Rainfall and Temperature Variability over Nigeria. Global Journal of Human-Social Science: B Geography, Geo-Sciences, Environmental Disaster Management, 14, 19.

[38] Oluwatobi, A. and Oluwakemi, O. (2016) Analysis of Trend and Variability of Atmospheric Temperature in Ijebu-Ode. Southwest Nigeria, 6, 25-31.

[39] National Bureau of Statistics (2013) Annual Abstract of Statistics. National Bureau of Statistics.

[40] National Bureau of Statistics (2011) Annual Abstract of Statistics. National Bureau of Statistics.

[41] Wang, X.L. (2008a) Accounting for Autocorrelation in Detecting Mean Shifts in Climate Data Series using the Penalized Maximal T or F Test. Journal of Applied Meteorology and Climatology, 47, 2423-2444.

https://doi.org/10.1175/2008JAMC1741.1 
[42] Wang, X.L. (2008b) Penalized Maximal F Test for Detecting Undocumented Mean Shift without Trend Change. Journal of Atmospheric and Oceanic Technology, 25, 368-384. https://doi.org/10.1175/2007JTECHA982.1

[43] Wang, X.L., Wen, Q.H. and Wu, Y. (2007) Penalized Maximal T Test for Detecting Undocumented Mean Change in Climate Data Series. Journal of Applied Meteorology and Climatology, 46, 916-931. https://doi.org/10.1175/JAM2504.1

[44] Nie, C., Li, H., Yang, L., Ye, B., Dai, E., Wu, S., Liao, Y., et al. (2012) Spatial and Temporal Changes in Extreme Temperature and Extreme Precipitation in Guangxi. Quaternary International, 263, 162-171. https://doi.org/10.1016/j.quaint.2012.02.029

[45] Trewin, B. (2013) A Daily Homogenized Temperature Data Set for Australia. International Journal of Climatology, 33, 1510-1529. https://doi.org/10.1002/joc.3530

[46] Wan, H., Wang, X.L. and Swail, V.R. (2010) Homogenization and Trend Analysis of Canadian Near-Surface Wind Speeds. Journal of Climate, 23, 1209-1225. https://doi.org/10.1175/2009JCLI3200.1

[47] Wang, X.L., Chen, H., Wu, Y., Feng, Y. and Pu, Q. (2010) New Techniques for the Detection and Adjustment of Shifts in Daily Precipitation Data Series. Journal of Applied Meteorology and Climatology, 49, 2416-2436. https://doi.org/10.1175/2010JAMC2376.1

[48] Vincent, L.A., Wang, X.L., Milewska, E.J., Wan, H., Yang, F. and Swail, V. (2012) A Second Generation of Homogenized Canadian Monthly Surface Air Temperature for Climate Trend Analysis. Journal of Geophysical Research Atmospheres, 117, D18110. https://doi.org/10.1029/2012JD017859

[49] Ceccherini, G., Russo, S., Ameztoy, I., Patricia, C.R. and Carmona-Moreno, C. (2016) Magnitude and Frequency of Heat and Cold Waves in Recent Decades: The Case of South America. Natural Hazards and Earth System Sciences, 16, 821-831. https://doi.org/10.5194/nhess-16-821-2016

[50] Ahmad, I., Tang, D., Wang, T., Wang, M. and Wagan, B. (2015) Precipitation Trends over Time using Mann-Kendall and Spearman's Rho Tests in Swat River Basin, Pakistan. Advances in Meteorology, 2015, Article ID: 431860.

[51] Burkey, J. (2006) A Non-Parametric Monotonic Trend Test Computing Mann-Kendall Tau, Tau-b, and Sen's Slope Written in Mathworks-MATLAB using Matrix Rotations. King County, Department of Natural Resources and Parks, Science and Technical Services Section, Seattle.

[52] Danneberg, J. (2012) Changes in Runoff Time Series in Thuringia, Germany-Mann-Kendall Trend Test and Extreme Value Analysis. Advances in Geosciences, 31, 49-56. https://doi.org/10.5194/adgeo-31-49-2012

[53] Salami, A.W., Mohammed, A.A., Abdulmalik, Z.H. and Olanlokun, O.K. (2014) Trend Analysis of Hydro-Meteorological Variables using the Mann-Kendall Trend Test: Application to the Niger River and the Benue Sub-Basins in Nigeria. International Journal of Technology, 5, 100-110. https://doi.org/10.14716/ijtech.v5i2.406

[54] Soltani, M. and Mofidi, A. (2013) Using Mann-Kendall and Time Series Techniques for Statistical Analysis of Long-Term Precipitation in Gorgan Weather Station. World Applied Sciences Journal, 28, 902-908.

[55] Wang, X.L. and Swail, V.R. (2001) Changes of Extreme Wave Heights in Northern Hemisphere Oceans and Related Atmospheric Circulation Regimes. Journal of Climate, 14, 2204-2221. https://doi.org/10.1175/1520-0442(2001)014<2204:COEWHI >2.0.CO;2 
[56] Cheng, J., Xu, Z., Zhu, R., Wang, X., Jin, L., Song, J. and Su, H. (2014) Impact of Diurnal Temperature Range on Human Health: A Systematic Review. International Journal of Biometeorology, 58, 2011-2024.

https://doi.org/10.1007/s00484-014-0797-5 